\title{
Veno-veno-arterial extracorporeal membrane oxygenation treatment in patients with severe acute respiratory distress syndrome and septic shock
}

\author{
Hye Ju Yeo ${ }^{1}$, Doosoo Jeon ${ }^{1}$, Yun Seong Kim¹, Woo Hyun Cho ${ }^{1}$ and Dohyung Kim² ${ }^{2^{*}}$
}

In acute respiratory distress syndrome (ARDS) with refractory septic shock, isolated veno-venous (VV) or veno-arterial (VA) extracorporeal membrane oxygenation (ECMO) may lead to differential hypoxia or inadequate tissue perfusion [1]. In this context, MacLaren et al. [2] showed that central ECMO improved the outcomes by guaranteeing systemic oxygenation without differential hypoxia. However, central ECMO has potential limitations due to its invasiveness and the lack of evidence in adult populations. Veno-veno-arterial (VVA) ECMO may offer effective oxygenation and hemodynamic support without differential hypoxia by regulating the return of oxygenated blood to the underperfused coronary and cerebral circulation [3-5]. Therefore, VVA mode can be an alternative treatment modality for ARDS patients with severe septic shock.

From October 2013 to March 2015, eight patients experienced septic shock with ARDS (seven men and one woman; average age $50.9 \pm 5.9$ years, range 18-71 years; five pneumonia-associated sepsis and three extrapulmonary sepsis). The baseline patient characteristics are summarized in Additional file 1.

Before ECMO, the median mean arterial pressure (MAP) was $40 \mathrm{mmHg}$ (interquartile range (IQR) 33-46), the median arterial lactate level was $7.8 \mathrm{mmol} / \mathrm{L}$ (IQR 6.3-16.3), and the median left ventricular ejection fraction was $42.5 \%$ (IQR 23.5-50.0). Despite adequate fluid and vasopressor therapy, refractory shock proceeded. The median amount of fluid received was 4.7 l (IQR 4.3-4.9) and the median central venous oxygen saturation was $81.2 \%$ (IQR 76.9-87.5). The median dose of norepinephrine was $0.7 \mu \mathrm{g} / \mathrm{kg} / \mathrm{min}$ (IQR $0.6-0.8$; also, vasopressin was used in all patients and six of the eight patients were also treated with epinephrine). All of the patients met the criteria for severe ARDS with a median $\mathrm{PaO}_{2} / \mathrm{FiO}_{2}$ of 57 (IQR 51.3-76.2; Table 1). The Institutional Review Board of Pusan National University Yangsan Hospital approved this study and waived the need for informed consent.

After VVA ECMO support, MAP increased, while the vasopressor dose and lactate level decreased and adequate oxygenation was sustained (Table 2). The median duration of vasopressor therapy was $24 \mathrm{~h}$ (IQR 18-72) and the median duration of VVA ECMO was 3.0 days (IQR 2.0-4.5). After 3 days, all patients had fully recovered from the refractory shock and they did not develop differential hypoxia. In addition, all patients were successfully weaned from arterial support and vasopressor. The overall survival rate was $50.0 \%$, and the successful weaning rate was $62.5 \%$. The number of patients is not enough to evaluate the feasibility, but VVA ECMO might be an alternative bridging strategy to assist the heart and lungs in patients with combined cardiopulmonary failure.

* Correspondence: yumccs@nate.com

${ }^{2}$ Department of Thoracic and Cardiovascular Surgery, Pusan National

University Yangsan Hospital, the Research Institute for Convergence of

Biomedical Science and Technology, Pusan National University Yangsan

Hospital, Geumo-ro 20, Beomeo-ri, Mulgeum-eup, Yangsan-si,

Gyeongsangnam-do 626-770, Republic of Korea

Full list of author information is available at the end of the article 
Table 1 Hemodynamics and arterial blood gas parameters before ECMO

\begin{tabular}{|c|c|c|c|c|c|c|c|c|c|c|c|}
\hline Patient & Sex/Age & EF (\%) & MAP $(\mathrm{mmHg})$ & $\mathrm{P} / \mathrm{F}$ ratio $(\mathrm{mmHg})$ & $\mathrm{PaCO} 2(\mathrm{mmHg})$ & $\mathrm{pH}$ & $\begin{array}{l}\text { Lactate } \\
(\mathrm{mmol} / \mathrm{L})\end{array}$ & Norepinephrine $^{a}$ & Vasopressin ${ }^{a}$ & Fluid (L) & ScvO2 (\%) \\
\hline 1 & $F / 18$ & 18 & 47 & 83.0 & 30 & 7.19 & 8.5 & 0.8 & 0.04 & 4.7 & 80.0 \\
\hline 2 & $M / 54$ & 50 & 43 & 52.0 & 29 & 7.18 & 6.2 & 1.0 & 0.04 & 4.6 & 82.3 \\
\hline 3 & $M / 51$ & 10 & 28 & 58.0 & 34 & 7.26 & 7.1 & 0.7 & 0.04 & 4.2 & 75.0 \\
\hline 4 & $M / 36$ & 50 & 49 & 71.5 & 30 & 7.17 & 13.5 & 0.5 & 0.04 & 5.0 & 86.0 \\
\hline 5 & $M / 64$ & 40 & 33 & 77.8 & 83 & 6.90 & 17.2 & 0.7 & 0.04 & 5.3 & 79.5 \\
\hline 6 & $M / 71$ & 40 & 33 & 56.0 & 45 & 7.10 & 6.5 & 0.7 & 0.04 & 4.5 & 92.0 \\
\hline 7 & $M / 53$ & 45 & 42 & 51.0 & 36 & 7.17 & 18.0 & 0.7 & 0.04 & 4.7 & 88.0 \\
\hline 8 & $\mathrm{M} / 60$ & 50 & 38 & 41.0 & 43 & 7.28 & 3.0 & 0.5 & 0.04 & 3.8 & 76.0 \\
\hline
\end{tabular}

ECMO extracorporeal membrane oxygenation, MAP mean arterial pressure syndrome, $\mathrm{P} / \mathrm{F}$ ratio $\mathrm{PaO}_{2} / \mathrm{FiO}_{2}$ ratio, $\mathrm{ScVO}_{2}$ central venous oxygen saturation (\%) ${ }^{\text {a }}$ The dose is in $\mu \mathrm{cg} / \mathrm{kg} / \mathrm{min}$

Table 2 Hemodynamic changes during WA ECMO support

\begin{tabular}{|c|c|c|c|c|c|}
\hline & Baseline & $6 \mathrm{~h}$ & $12 \mathrm{~h}$ & $24 \mathrm{~h}$ & $72 \mathrm{~h}$ \\
\hline LVEF (\%) & $42.5[23.5-50.0]$ & & & $50.0[40.0-50.0]$ & $50.0[40.0-55.0]$ \\
\hline \multirow[t]{2}{*}{ MAP $(\mathrm{mmHg})$} & 40.0 & 76.0 & 74.0 & 85.5 & 83.0 \\
\hline & [33.0-46.0] & {$[62.8-101.3]$} & [71.0-101.0] & [75.3-88.3] & {$[67.3-94.3]$} \\
\hline Norepinephrine ${ }^{a}$ & $0.7[0.6-0.8]$ & $0.5[0.2-0.6]$ & $0.3[0-0.6]$ & $0.1[0-0.1]$ & $0[0-0]$ \\
\hline Epinephrine $^{a}$ & $0.1[0.0-0.2]$ & $0[0-0.1]$ & $0[0-0]$ & $0[0-0]$ & $0[0-0]$ \\
\hline \multicolumn{6}{|l|}{ Arterial gas profile } \\
\hline \multirow[t]{2}{*}{$\mathrm{PaO}_{2} / \mathrm{FiO}_{2}$} & 57.0 & 102.3 & 133.0 & 147.0 & 162.5 \\
\hline & {$[51.3-76.2]$} & {$[80.3-190.0]$} & [102.0-413.0] & [111.8-184.0] & [137.3-227.5] \\
\hline Lactate (mmol/L) & $7.8[6.3-16.3]$ & $5.5[2.5-14.8]$ & $6.3[2.0-15.5]$ & $7.0[3.0-14.0]$ & $5.0[2.0-5.0]$ \\
\hline $\mathrm{pH}$ & $7.2[7.1-7.2]$ & $7.4[7.3-7.5]$ & $7.4[7.3-7.4]$ & $7.4[7.4-7.5]$ & $7.5[7.4-7.5]$ \\
\hline
\end{tabular}

The data are presented as median [interquartile range]

VVA veno-venoarterial, ECMO extracorporeal membrane oxygenation, $L V E F$ left ventricle ejection fraction, MAP mean arterial pressure

${ }^{\text {a }}$ The dose is in $\mu \mathrm{cg} / \mathrm{kg} / \mathrm{min}$ 


\section{Additional file}

Additional file 1: Baseline patient characteristics. $F$ female, $M$ male. (DOCX $15 \mathrm{~kb}$ )

\section{Abbreviations}

ARDS: Acute respiratory distress syndrome; ECMO: Extracorporeal membrane oxygenation; IQR: Interquartile range; MAP: Mean arterial pressure; VA: Venoarterial; W: Veno-venous; WA: Veno-veno-arterial.

\section{Competing interests}

The authors declare that they have no competing interests.

\section{Authors' contributions}

HJY carried out the acquisition of data, data review and manuscript preparation. WHC and DJ participated in the evaluation of ethical issues and performed data review. DK and YSK participated in the conception and coordination of the study and helped to draft the manuscript. All authors read and approved the final manuscript.

\section{Author details}

'Department of Internal medicine, Pusan National University Yangsan Hospital, Medical Research Institute of Pusan National University, Geumo-ro 20, Beomeo-ri, Mulgeum-eup, Yangsan-si, Gyeongsangnam-do 626-770, Republic of Korea. ${ }^{2}$ Department of Thoracic and Cardiovascular Surgery, Pusan National University Yangsan Hospital, the Research Institute for Convergence of Biomedical Science and Technology, Pusan National University Yangsan Hospital, Geumo-ro 20, Beomeo-ri, Mulgeum-eup, Yangsan-si, Gyeongsangnam-do 626-770, Republic of Korea.

\section{Published online: 10 February 2016}

\section{References}

1. Avgerinos DV, DeBois W, Voevidko L, Salemi A. Regional variation in arterial saturation and oxygen delivery during venoarterial extracorporeal membrane oxygenation. J Extra Corpor Technol. 2013;45:183-6.

2. MacLaren G, Butt W, Best D, Donath S. Central extracorporeal membrane oxygenation for refractory pediatric septic shock. Pediatr Crit Care Med. 2011;12:133-6.

3. Shekar K, Mullany DV, Thomson B, Ziegenfuss M, Platts DG, Fraser JF. Extracorporeal life support devices and strategies for management of acute cardiorespiratory failure in adult patients: a comprehensive review. Crit Care. 2014;18:219

4. Ius F, Sommer W, Tudorache I, Avsar M, Siemeni T, Salman J, et al. Venoveno-arterial extracorporeal membrane oxygenation for respiratory failure with severe haemodynamic impairment: technique and early outcomes. Interact Cardiovasc Thorac Surg. 2015:20:761-7.

5. Umei N, Ichiba S, Ujike Y, Tsukahara K. Successful application of venoarterialvenous extracorporeal membrane oxygenation in the reversal of severe cardiorespiratory failure. BMJ Case Rep. 2015. doi:10.1136/bcr-2015-209901. 